Article

\title{
Land Border Tourism Resources in China: Spatial Patterns and Tourism Management
}

\author{
Shengrui Zhang ${ }^{1,2} \mathbb{D}^{\text {, Linsheng Zhong }}{ }^{1,2}$, Hongrun $\mathrm{Ju}^{3}$ and Yingjie Wang ${ }^{1,2, *}$ \\ 1 Institute of Geographic Sciences and Natural Resources Research, Chinese Academy of Sciences, \\ Beijing 100101, China; zhangsr.12s@igsnrr.ac.cn (S.Z.); zhongls@igsnrr.ac.cn (L.Z.) \\ 2 University of Chinese Academy of Sciences, Beijing 100049, China \\ 3 School of Tourism and Geography Science, Qingdao University, Qingdao 266071, Shandong, China; \\ jhr621@126.com \\ * Correspondence: wangyj@igsnrr.ac.cn; Tel.: +86-010-6488-9077
}

Received: 1 December 2018; Accepted: 28 December 2018; Published: 4 January 2019

\begin{abstract}
Land border tourism in China serves as a pillar industry in local economic development and is an important sector for international cooperation. This paper aims to fill the gap in the spatial pattern of land border tourism resources in China using geographical information systems (GIS) and spatial statistical methods. The pattern was analyzed from the aspects of numerical features, spatial variance, and spatial association at different spatial scales. The results show that 3341 land border tourism resources in China reveal significant clusters and outliers at both the prefectural and county scales, offering useful information for the management of tourism resources. Physical factors, cultural diversity, regional policies, the relationships between neighboring countries, and public facilities are shown to be the main factors influencing the patterns. It is suggested that the government should adjust its management policies based on the characteristics of local resources, conduct combinatorial development of different types of resources, strengthen the cooperation domestically and internationally, improve public facilities, and protect the local environment and ethnic culture.
\end{abstract}

Keywords: land border tourism resources; spatial association; spatial variance; GIS; Moran's I; tourism management; China

\section{Introduction}

The number of international tourist arrivals, including border tourists, increased to a total of 1235 million (3.9\%) from 2015 to 2016 (http:/ / www2.unwto.org). As an important part of international tourism, the demand for border tourism has also increased robustly in recent years. In many countries, border tourism has become an important sector as a growing source of foreign exchange earnings, and has created employment opportunities for the border areas [1-3]. In addition, border tourism makes a big contribution to the promotion of mutual understanding among people from different countries that have different religious beliefs and cultures, which is important for regional stability and sustainable development in the border areas [4-6]. Current research on border tourism was mainly focused on basic theories, tourism perceptions, tourism effects, and tourism management. Timothy proposed that national borders could act as barriers to travel, attractions to tourists, and modification of the tourist landscape [7]. By comparing the degree of difficulty for tourists in crossing the border and the degree of similarity in the cultures or societies located on both sides, Timothy further classified four border types for tourist crossings [2]. As for tourism perception, it was found that economic, quality, service variables, and the affective pleasure of vacationing in a foreign environment exert effects on vacationers' perceptions, behavior, and satisfaction [8]. The positive and negative impacts on the 
social, economic, and environmental development of border tourism also have attracted the attention of many researchers [4,9-11]. The particular location and political sensitivity of the border areas make the management of the border tourism more important and complicated. The cooperation mode, cooperation policies, laws and regulations, and their effects of various tourism sites were analyzed as research hotspots [12-15].

The tourism resources in the land border areas in China are extremely abundant. China has the longest land border and the largest number of land neighboring countries in the world. The land border starts from the Yalu River Estuary and ends at the North Bay area, covering more than 22,000 km and about 32 latitudes and 60 longitudes. The natural environment, socioeconomic conditions, culture, and history in these areas vary significantly. The geographical landscapes are spectacular with many famous geographical entities across the border, such as the Himalayas, Tian Shan, Altai Mountain, Changbai Mountain, and Brahmaputra. At the same time, there are many well-known trans-boundary rivers, such as Yalu River (Amnok River), Ussuri River, Heilong River (Amur River), Irtysh River (Ob River), Ili River, Brahmaputra River and Lancang River (Mekong River), which flow on the borders between China and the neighboring countries. Accompanied by these large-scale geographical entities are many world-famous tourism resources, such as the Detian Waterfalls, the Xishuangbanna Botanical Gardens, Kanas Lake, Everest Base Camp, and the Brahmaputra Grand Canyon. In addition, there are 14 neighboring countries of China and nearly 40 minority ethnic groups living in the land border areas in China, with colorful national culture, minority ethnic culture, and traditional folk customs. The characteristics of land border tourism resources in China could be summarized as follows: Many resources, a wide range of space, and diversity in physical and human features.

However, the potential value of the resources along the land border in China deserves better development and exploitation. Due to the complex terrain and harsh climate of the land border areas, most of the population lives in the eastern coastal areas of China. The development between the coastal areas and land border areas has been extremely uneven with a heavy population, rapid industrialization, and modernization in the east and vice versa in the land border areas. The unbalanced development between border areas and inland/coastal areas has sparked the attention of the central government. In 2011, the land border areas were confirmed as Contiguous Destitute Areas by the State Council of China and became the key areas of Targeted Poverty Alleviation. In 2013, "The Belt and Road Initiative" was proposed and aimed to build a cohesive economic area including some neighboring countries in Central Asia and West Asia. In December 2015, a document was further published aiming at supporting the development and opening-up of major border areas, and land border tourism was identified as one important measure to boost border development. These positive policies indicate booming exploitation of land border tourism in the near future.

The current work mainly explores the spatial patterns of tourism resources by qualitative descriptions and focuses on a small number of specific border tourism resources. In order to fill these gaps, this study systematically clarifies the spatial patterns of land border tourism resources in China using GIS technology and spatial statistical methods. The spatial patterns of different types of land border tourism resources in China are first analyzed from three aspects (the numerical features, the spatial variation, and the spatial association) at different spatial scales. Then, the influencing factors, including the physical, socioeconomic, and political factors of the spatial pattern of land border tourism resources, are discussed. Based on these results, helpful information is provided for the management of land border tourism resources to guide their development in the future.

\section{Literature Review}

With the boom of the tourism industry, the understanding and concept of border tourism is developing at the same time. There is no unified definition of border tourism and the expression of "border and tourism", "border as attractions", and "cross border tourism" are widely used in related research fields. Sofield first used the term "border tourism" to explore the social and cultural spaces of border communities and visitation involving travel across the borders of sovereign states [1]. 
According to the World Tourism Organization, border tourists are those who stay on the frontier for 24-72 $\mathrm{h}$ [16]. Bringas defined border tourism as the temporary movement of people outside their usual place of residence to the boundary between two countries in adjacent cities, for the purpose of leisure, entertainment, health, business, visits to relatives and/or friends, religion, social events, or shopping, whose stay varied from one night to one year in the visited place [17]. According to these concepts, we can get three features of border tourism: First, the tourism attractions are located near the border areas of a country; second, the displacement to the border destinations is temporary in the short term; and third, the tourist activities are international travel for purposes not related to paid work.

The special function and location of border areas offer various motivations for tourists. Borderlines themselves and the way they are marked can be significant tourism objects. For instance, The Berlin Wall was West Berlin's primary tourist attraction before 1989, and since then, officials have made considerable effort to conserve parts of it [7]. In addition, border tourism destinations are often characterized by the political and socio-economic advantages that they offer, such as lower taxes or more permissive policies, favoring the development of certain types of tourism [18]. For tourists, consumption and shopping, sightseeing, and folk custom experiences are the most popular types of motivation for border tourism [19-21]. For the government, cooperation in land border tourism development could increase the incomings of residents while preventing the environment from being damaged.

The study of border tourism has adopted theories from many related subjects, such as tourism, geopolitics, economic geography, and public administration. In the view of tourism, researchers often consider the tourism supply, tourist demand, and satisfaction [2,22-24]. In the view of geopolitics, scholars have noticed the positive impact of the geopolitical landscape of the world and its evolution on international relations $[9,25,26]$. In the field of economic geography, the center-edge (CE) theory was widely applied to explain why the border area development is far inferior to that of the inland or costal area $[27,28]$. Other theories, like system theory, game theory, distance decay theory, space production theory, and sustainable development theory, all have been applied in border tourism research [1,27,29-32].

As for the study areas, Europe is the hottest area for the land border tourism study. Bothnian Arc and Tornio Valley along the borders between Finland-Sweden [33,34], Baarle-Hertog and Baarle-Nassau along the border between Netherlands-Belgium [18], and Cerdanya Valley-Catalan Pyrenees along the border between France-Spain [35] are all popular areas for border tourism. North America is another important area for this study [9,24]. In contrast, border tourism in Asia is less studied, which reveals a lack of exploration of the tourism resources of these areas.

The traditional studies on the land border tourism resources concentrated on the classification and statistics of tourism resources [36-39]. Recently, the number of studies on the spatial pattern of border tourism resources has grown significantly [40-45]. However, the analysis methods of the spatial patterns of land border tourism resources are limited to traditional qualitative methods, and spatial analysis methods are less used. Due to the data limitations and the complex classification of land border tourism resources, most of the research has been restricted to one administrative unit and a few tourism resources. For instance, Timothy examined cross-border partnerships in three international parks along the US-Canada border based on principles of sustainable tourism [12]; however, there were other tourism resources on the border that were worth analyzing and reflected the partnerships. Despite the considerable body of literature on specific cases of border tourism and how they affect travel behaviors, very little research has been conducted regarding a whole view of the border tourism resources of a country. Few seem to be looking into the spatial pattern of different types of resources and the underlying knowledge implied for the management of the resources. 


\section{Data and Methods}

\subsection{Data Source}

According to the definition of border tourism in the literature review, the land border tourism resources in this paper refer to tourism destinations that are located at the land border areas, which could present considerable opportunity for the development of the border areas. In this study, the land border areas were defined as the counties along the terrestrial borders in China, and the land border tourism resources in China were restricted to this area (Figure 1c). The data from land border tourism resources in China were acquired from four sources: Tourism planning of the border counties, academic documents, the official travel websites of the land border counties, and field surveys carried out from 2000 to 2014 . The field surveys covered 27 county units in the different parts of the land border areas, including Tumen city, Longjing city, Hunchun city, Helong city, Antu county, Jiayin county, Luobei county, Manzhouli city, and Erenhot city in northeast China; Burqin county, Tajik autonomous county of Taxkorgan, Urad back banner, and Urad middle banner in northwest China; and Dingri county, Yao autonomous county of Hekou, Miao-Yao-Dai autonomous county of Jinping, Lvchun county, Menghai county, Mengla county, Jinghong city, Jingxi county, Napo county, Daxin county, Ningming county, Longzhou county, Fangcheng district, Pingxiang city and Dongxing city in southwest China. The survey was conducted on the tourist attractions or scenic areas rated as A level and above according to the China National Tourism Administration. The survey clarified the locations, types, properties, and characteristics, the surrounding environment, and the protection and development conditions of land border tourism resources. In addition, investigation questionnaires were designed for the local experts and government staff in order to determine the development conditions of the tourism resources. As for these surveyed counties, only the attribute of types of tourism resources were used for this paper.

According to the China National Standard "Classification, investigation and evaluation of tourism resources (GB/T 18972-2003)", the tourism resources were divided into eight categories: Geological landscapes, water landscapes, biological landscapes, astronomical phenomena and meteorological landscapes, ruins and remains, construction and facilities, human activities, and tourism commodities. The eight first-level types can be further divided into 31 subtypes and 155 fundamental types. In this study, the land border tourism resources covered 31 subtypes and 142 fundamental types (Table 1).

\subsection{Spatial Scales}

Scale effects were determined as the variation in results when data for one set of areal units were progressively aggregated into fewer and larger units for analysis [46]. Such effects existed universally in geographical phenomena and in spatial analyses. In order to comprehensively analyze the spatial pattern of land border tourism resources in China, the spatial pattern was explored at three scales: Border scale, prefectural scale, and county scale (Figure 1).

Crossing the land border, there are 14 neighboring countries of China, nine provincial units, 45 prefectural units, and 138 county units in China. The divisions of prefectural and county units were based on the administrative divisions in 2014 to avoid the data inconsistency caused by the adjustment of administrative divisions over time. At border scale, there are fourteen land neighbors of China: Vietnam, Laos, Myanmar, India, Nepal, Bhutan, Pakistan, Afghanistan, Tajikistan, Kyrgyzstan, Kazakhstan, Mongolia, Russia, and North Korea (Figure 1a). At the prefectural scale, based on the administration divisions of the National Bureau of Statistics of China (http:/ / www.stats.gov.cn/tjsj/ tjbz/xzqhdm/), 45 units were derived, including 25 prefecture-level cities, 10 autonomous prefectures, seven prefectures, and 3 leagues (Figure 1b). At the county scale, 138 units were derived, including 72 counties, 27 county-level cities, 17 autonomous counties, 15 banners, and 7 districts (Figure 1c). 


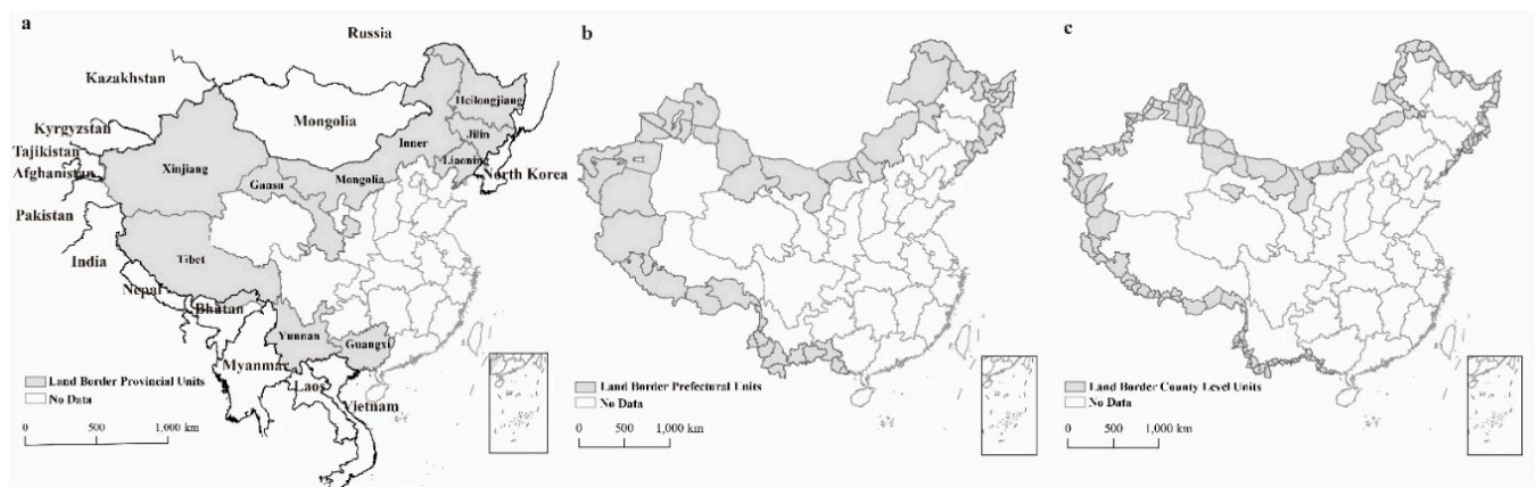

Figure 1. The spatial divisions at border scale, prefectural scale, and county scale along the land border in China (a) the land border provinces and neighboring countries of China; (b) the land border prefectures; (c) the land border counties (for the names of prefectural units and county units, see the Supplementary Materials).

\subsection{Spatial Pattern Indicators}

At each scale, we describe the spatial pattern of land border tourism resources from three aspects: The numerical features, the spatial variation, and the spatial association. The coefficient of variation $(\mathrm{CV})$ was used to depict the spatial variation, while the global and local Moran's I indexes were used to test the global and local spatial associations of land border tourism resources.

\subsubsection{Spatial Variation Indicator}

The $C V$ was selected to measure the spatial variation of land border tourism resources at different scales. It is often expressed as a percentage and is defined as the ratio of the standard deviation $(S D)$ to the mean (Equations (1) and (2)) [47]. It was considered to be more reasonable to use the $C V$ than the $S D$ in this study because the $S D$ must always be understood in the context of the mean of the data, which varied among the different scales used in this study. In contrast, the value of the $C V$ was independent of the unit (or the mean) in which the measurement was made [47]. In this study, using the $C V$ allowed for a comparison of the spatial variation of land border tourism resources among different scales, which have widely different means.

$$
\begin{gathered}
S D=\sqrt{\frac{1}{n} \sum_{i=1}^{n}\left(X_{i}-\bar{X}\right)^{2}} \\
C V=S D / \bar{X}
\end{gathered}
$$

where the $C V$ is the coefficient of variation; $S D$ is the standard deviation; $n$ is the number of divisions at a given scale $\left(n=14,45\right.$, and 138 at the border, prefectural, and county scales, respectively); $X_{i}$ is the land border tourism resources of the $i$ th division at a given scale $(i=1,2, \ldots, n)$; and $\bar{X}$ is the mean number of land border tourism resources of the divisions. The larger the $C V$ value is, the more spatial variation in land border tourism resources there is.

\subsubsection{Spatial Association Indicators}

Spatial association statistics are used to evaluate the existence of clusters in the spatial arrangement of a given variable. In this study, the global Moran's I and local Moran's I were used to analyze the global and local spatial associations of land border tourism resources, respectively. The spatial association statistics require the geographical relationship of the divisions to be modelled. For both analyses, a matrix of spatial weighting is used to conceptualize the spatial relationships and express how strong the influence is between the divisions. We used a spatial weighting matrix that took 
distance into consideration. It assumed that the effects between nearby regions were large, and vice versa. In this matrix, the weightings vary in terms of an inverse relation to the distance among divisions:

$$
w_{i j}=1 / d_{i j}
$$

where $w_{i j}$ is the elements of the weighting matrix; $d_{i j}$ is the distance between the center of gravity of region $i$ and region $j$. The matrix is standardized in such a way that the rows sum to one by dividing each value by the row sum of the original matrix. The border scale was omitted from the spatial association analysis because of the small size of its divisions.

(1) Global indicators of spatial association

Global indicators of association measure if, and how much, the dataset is associated throughout the study region. One of the principal global indicators of association is the Moran's I. It estimates the overall degree of spatial association for a dataset [48]:

$$
\text { Global Moran's } I=\frac{n}{\sum_{i=1}^{n} \sum_{j=1}^{n} w_{i j}} \frac{\sum_{i=1}^{n} \sum_{j=1}^{n} w_{i j}\left(X_{i}-\bar{X}\right)\left(X_{j}-\bar{X}\right)}{\sum_{i=1}^{n}\left(X_{i}-\bar{X}\right)^{2}}
$$

where $n$ is the number of spatial divisions; $X_{i}$ and $X_{j}$ are the land border tourism resources in divisions $i$ and $j(i \neq j) ; \bar{X}$ is the average value; and $w_{i j}$ is the matrix of spatial weights. The values of the global Moran's I range from -1 to +1 . Positive values indicate a positive association, i.e., the clustering of similar values across the geographic space. In contrast, negative values indicate a negative association. This means that neighboring values are more dissimilar than expected by chance, suggesting a spatial pattern similar to a chess board. Theoretically, if Moran's I converge to zero, it indicates a random spatial pattern.

(2) Local indicators of spatial association (LISA)

LISA allows us to locate clustered patterns by comparing the values in each specific location with values in neighboring locations. The local Moran's I statistic was calculated in order to map the presence of these clusters at the local level. The method has been used widely in the tourism field to identify local clusters or outliers [49-51]. In this study, we used the local Moran's I index (Equation (5)) to identify different spatial association patterns, including high-high clusters, low-low clusters, high-low outliers, and low-high outliers [52]. High-high clusters were areas with many land border tourism resources that were surrounded by neighboring areas also with many land border tourism resources, while low-low clusters were areas with few land border tourism resources that were surrounded by neighboring areas also with few land border tourism resources. These two patterns were positive spatial associations. In contrast, spatial outliers were identified when a region with many land border tourism resources was surrounded by neighboring regions with few land border tourism resources and vice versa.

$$
\text { Local Moran's } I=\frac{X_{i}-\bar{X}}{S_{i}^{2}} \sum_{j=1, j \neq i}^{n} w_{i j}\left(X_{j}-\bar{X}\right)
$$

where $S_{i}^{2}$ is the variance of land border tourism resources, and the other symbols are the same as described above. A high positive local Moran's I value implies that an area has similarly high or low values as its neighbors, while a high negative local Moran's I value means the location is significantly different from the surrounding areas. The local Moran's I can be standardized thus that its significance level can be tested based on the assumption of a normal distribution $[53,54]$. 


\section{Results}

\subsection{Overall Quantity of Land Border Tourism Resources in China}

There are 3341 land border tourism resources in China, and the quantity of different resources is extremely uneven. The largest type of land border tourism resource is buildings and facilities, accounting for $38.37 \%$ of all resources. The second-largest and third-largest types are geological landscapes and water landscapes, with proportions of $16.97 \%$ and $14.61 \%$ of the total number, respectively. The numbers of ruins and remains, human activities, biological landscapes, and tourism commodities are between 200 and 300. In contrast, astronomical phenomena and meteorological landscapes have the fewest land border tourism resources with a proportion of only $0.81 \%$ (Table 1 ). The numbers of their subtypes are also unbalanced. The largest subtype is comprehensive cultural tourism destinations, which accounts for nearly twice the number of resources as comprehensive natural tourist destinations. The smallest three subtypes are estuaries and sea landscapes, flower landscapes, and light landscapes, which all have numbers below 10. As for the fundamental types, only eight types have more than 100 tourism resources, while 72 types have less than 10 tourism resources (Table 2). The largest fundamental types are hills and religious and sacrificial sites, both having 183 tourism resources. The smallest fundamental type is bore phenomena which only has one tourism resource. 
Table 1. The number of land border tourism resources of different types in China.

\begin{tabular}{|c|c|c|c|c|c|c|}
\hline \multicolumn{3}{|c|}{ Main Types } & \multicolumn{2}{|l|}{ Subtype } & \multicolumn{2}{|c|}{ Fundamental Type } \\
\hline The Types & Number & $\begin{array}{l}\text { Proportion of the } \\
\text { Total Number (\%) }\end{array}$ & The Types & Number & $\begin{array}{l}\text { Number of the } \\
\text { Types }\end{array}$ & $\begin{array}{c}\text { Proportion of the } \\
\text { National Standard (\%) }\end{array}$ \\
\hline A Geological Landscapes & 567 & 16.97 & $\begin{array}{l}\text { AA Comprehensive Natural Tourist Destinations } \\
\text { AB Sedimentaries and Tectonic Landscapes } \\
\text { AC Geological and Geomorphological Ruins } \\
\text { AD Natural Change Ruins } \\
\text { AE Islands }\end{array}$ & $\begin{array}{c}293 \\
56 \\
169 \\
12 \\
37\end{array}$ & 29 & 78.38 \\
\hline B Water Landscapes & 488 & 14.61 & $\begin{array}{l}\text { BA Rivers } \\
\text { BB Natural Lakes and Ponds } \\
\text { BC Waterfalls } \\
\text { BD Springs } \\
\text { BE Estuaries and Sea Landscapes } \\
\text { BF Ice Landscapes }\end{array}$ & $\begin{array}{c}126 \\
163 \\
63 \\
97 \\
5 \\
34\end{array}$ & 14 & 93.33 \\
\hline C Biological Landscapes & 233 & 6.97 & $\begin{array}{l}\text { CA Forest Landscapes } \\
\text { CB Steppe Landscapes } \\
\text { CC Flower Landscapes } \\
\text { CD Wild Animal Habitats }\end{array}$ & $\begin{array}{c}152 \\
40 \\
7 \\
34\end{array}$ & 11 & 100.00 \\
\hline $\begin{array}{l}\text { D Astronomical Phenomena and } \\
\text { Meteorological Landscapes }\end{array}$ & 27 & 0.81 & $\begin{array}{l}\text { DA Light Landscapes } \\
\text { DB Meteorological Landscapes }\end{array}$ & $\begin{array}{l}10 \\
17\end{array}$ & 7 & 87.50 \\
\hline E Ruins and Remains & 289 & 8.65 & $\begin{array}{l}\text { EA Prehistoric Human Activity Places } \\
\text { EB Socio-economic and Cultural Ruins }\end{array}$ & $\begin{array}{c}34 \\
255\end{array}$ & 11 & 91.67 \\
\hline F Buildings and Facilities & 1282 & 38.37 & $\begin{array}{l}\text { FA Comprehensive Cultural Tourism Destinations } \\
\text { FB Single Functional Halls } \\
\text { FC Landscape Architecture and Ancillary Buildings } \\
\text { FD Residences and Communities } \\
\text { FE Cemeteries } \\
\text { FF Traffic Architecture } \\
\text { FG Hydraulic Architecture }\end{array}$ & $\begin{array}{l}570 \\
55 \\
240 \\
181 \\
112 \\
37 \\
87\end{array}$ & 47 & 95.92 \\
\hline G Tourism Commodities & 205 & 6.14 & GA Local Tourism Commodities & 205 & 7 & 100.00 \\
\hline H Human Activities & 250 & 7.48 & $\begin{array}{l}\text { HA Personnel Records } \\
\text { HB Arts } \\
\text { HC Folk Customs } \\
\text { HD Modern Festivals }\end{array}$ & $\begin{array}{c}31 \\
19 \\
159 \\
41\end{array}$ & 16 & 100.00 \\
\hline Sum & 3341 & 100.00 & 31 & 3341 & 142 & 91.61 \\
\hline
\end{tabular}


Table 2. The quantities of the fundamental tourism resources in the land border counties of China.

\begin{tabular}{|c|c|c|}
\hline $\begin{array}{l}\text { The Quantity of } \\
\text { Tourism Resources }\end{array}$ & Fundamental Type & $\begin{array}{c}\text { The Number of } \\
\text { the Type }\end{array}$ \\
\hline$\geq 100$ & $\begin{array}{l}\text { Hills, religious and sacrificial site, sightseeing and recreational lake, recreational river, } \\
\text { abandoned cities and settlements, woodlands, recreational resort, food and diet }\end{array}$ & 8 \\
\hline $50-99$ & $\begin{array}{l}\text { Tombs, mountain valley, folk festival, border port, cliff painting, hot springs, } \\
\text { recreational reservoir, characteristic community }\end{array}$ & 8 \\
\hline $30-49$ & $\begin{array}{l}\text { Plunge waterfall, military sites, and ancient battlefields, traditional and local } \\
\text { architecture, stele, recreational garden, traditional handicrafts, cultural activities, } \\
\text { demonstration hall, rock caves, construction and production area, island, grasslands, } \\
\text { strange rocks, glacier sightseeing area, cold springs, former residence of celebrity }\end{array}$ & 16 \\
\hline $10-29$ & $\begin{array}{l}\text { Agricultural, forestry and livestock products, abandoned temple, architectural } \\
\text { sketches, biological fossils, single tree, human activity historical remains, canyon } \\
\text { landscape, animal and plants exhibition area, local customs and folk etiquette, folk } \\
\text { performing arts, tufa and sinter, terrestrial animal habitat, squares, scenery viewing } \\
\text { point, pagoda, bridge, characters, traffic remnants, military sightseeing area, tourist } \\
\text { festival, cemetery, wetlands, grotto, characteristic market, Chinese herbal medicines } \\
\text { and products, characteristic street, tower building, dam, literary and artistic works, } \\
\text { folk fitness activities and events, gravel and stones, multi-step waterfall, stone (soil) } \\
\text { forest, historic site, cultural festival, sandy land, volcano and lava, port ferry and wharf }\end{array}$ & 38 \\
\hline$<10$ & $\begin{array}{l}\text { Rocky beach, abandoned production area, beacon, The Great Wall, event, prominent } \\
\text { mountain, shore beach, cloudy area, gymnasium, pavilion, Single mountain peak, } \\
\text { Yardang landscape, dense forest, bird habitat, primitive settlement, social and } \\
\text { commercial activities held in area, natural landmark, rock wall or slot, flower meadow, } \\
\text { teaching and scientific research laboratory, religious activities, characteristic dresses, } \\
\text { sports festival, characteristic stores, diet customs, ore veins, pond, recreational } \\
\text { offshore, cosmic stars observation area, mirage phenomenon, summer resort, extreme } \\
\text { climate landscape, well, other items, strange natural phenomena, mountain peak } \\
\text { cluster, gully landscape, aquatic habitat, the great wall ruins, memorial hall, castle, } \\
\text { canals and channels, water extraction facilities, aquatic products, daily necessities, } \\
\text { literature and art organization, commercial festival, stratigraphic section, sparse forest } \\
\text { grassland, halo phenomenon, hanging coffins, station, path along the cliff, jointed rock } \\
\text { landscape, red cliffs, earthquake remains, glacial erosion remains, rock reef, } \\
\text { underground stream, ancient river course, bore phenomenon, snowy mountains, } \\
\text { flower forest, butterfly habitat, phenology landscape, cultural relics remains, reception } \\
\text { hall (room), academy, guild hall, airport, irrigation area, temple fair }\end{array}$ & 72 \\
\hline
\end{tabular}

\subsection{Spatial Patterns of Land Border Tourism Resources at the Border Level}

The borders between China and Vietnam, and China and Myanmar have the largest numbers of tourism resources at 617 and 532, respectively. However, the border between China and Mongolia, as the longest land border in China, has less tourism resources (488). The lowest numbers of tourism resources occur on the borders between China and Tajikistan (22) and China and Afghanistan (30). These two borders are also shorter than the others. In addition, the compositions of the different types of border tourism resources of most borders are similar: Buildings and facilities are the largest types, and the astronomical phenomena and meteorological landscapes are the smallest ones. However, water landscapes are the largest type on the borders between China and Bhutan, China and Afghanistan, and China and Tajikistan (Figure 2).

The spatial variation in the different types of land border tourism resources is different at the border scale. The $C V$ of the total land border tourism resources was $45.71 \%$. The $C V$ values of human activities and astronomical phenomena and meteorological landscapes were the highest, indicating that the spatial distribution of the two types is more uneven than that of the other types (Table 3). The human activities are mainly gathered on the border between China and Myanmar and the border between China and Vietnam, accounting for $43.60 \%$ of this type of resource. The astronomical phenomena and meteorological landscapes are mainly distributed on the border between China and Mongolia and the border between China and Russia, accounting for $40.74 \%$ of this type of resource. 


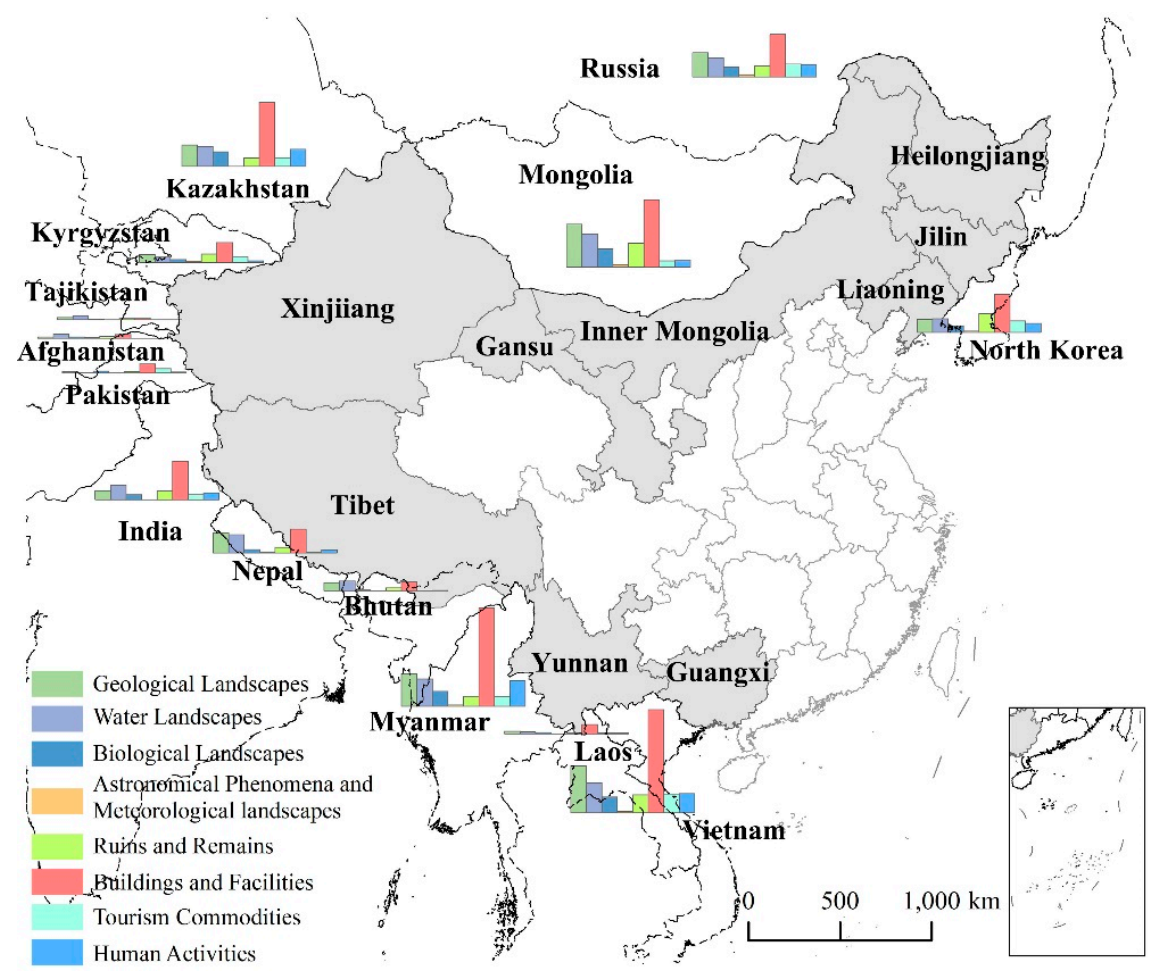

Figure 2. The structure of land border tourism resources at the border scale in China.

Table 3. $C V$ and Moran's I of land border tourism resources in China at different scales.

\begin{tabular}{|c|c|c|c|c|c|}
\hline \multirow{2}{*}{ Tourism Resources Types } & \multirow{2}{*}{$\begin{array}{c}\text { Border Scale } \\
C V(\%)\end{array}$} & \multicolumn{2}{|c|}{ Prefectural Scale } & \multicolumn{2}{|c|}{ County Scale } \\
\hline & & $C V(\%)$ & Moran's I & $C V(\%)$ & Moran's I \\
\hline Land Border Tourism Resources & 45.71 & 70.55 & $0.2618^{* *}$ & 68.72 & $0.3029 * *$ \\
\hline Geological Landscapes & 54.58 & 84.51 & $0.2041^{* *}$ & 108.08 & $0.1163^{* *}$ \\
\hline Water Landscapes & 41.41 & 86.57 & $0.1334 * *$ & 85.8 & $0.1304 * *$ \\
\hline Biological Landscapes & 54.75 & 74.11 & $0.1647 * *$ & 103.03 & 0.0477 * \\
\hline Astronomical Phenomena and Meteorological Landscapes & 66.17 & 150.72 & -0.0376 & 229.06 & 0.0023 \\
\hline Ruins and Remains & 47.32 & 99.38 & 0.0261 & 122.06 & $0.0585 * *$ \\
\hline Buildings and Facilities & 51.9 & 81.73 & $0.2780 * *$ & 87.78 & $0.3085^{* *}$ \\
\hline Tourism Commodities & 56.22 & 109.23 & $0.1121 *$ & 189.75 & 0.0271 \\
\hline Human Activities & 67.35 & 101.66 & 0.0988 * & 150.74 & $0.0803^{* *}$ \\
\hline
\end{tabular}

Notes: * indicates the value is significant at the 0.05 level and ${ }^{* *}$ indicates the value is significant at the 0.01 level.

\subsection{Spatial Patterns of Land Border Tourism Resources at the Prefectural Level}

At the prefectural scale, the quantity of land border tourism resources varies a lot among different prefectural units. Shigatse city in Tibet and Fangchenggang city in Guangxi have the largest number of land border tourism resources at 207 and 200, respectively. In contrast, Ulanqab city in Inner Mongolia, Tonghua city in Jilin, and Shuangyashan city in Heilongjiang have the smallest numbers of resources among all prefectural units (Figure 3). The distribution of land border tourism resources at the prefectural scale shows an obvious spatial variance. The $C V$ of land border tourism resources was $70.55 \%$, and the $C V$ s of astronomical phenomena and meteorological landscapes, tourism commodities, and human activities were higher than $100 \%$. Most types showed a greater variation at this scale than at the border scale (Table 3). 


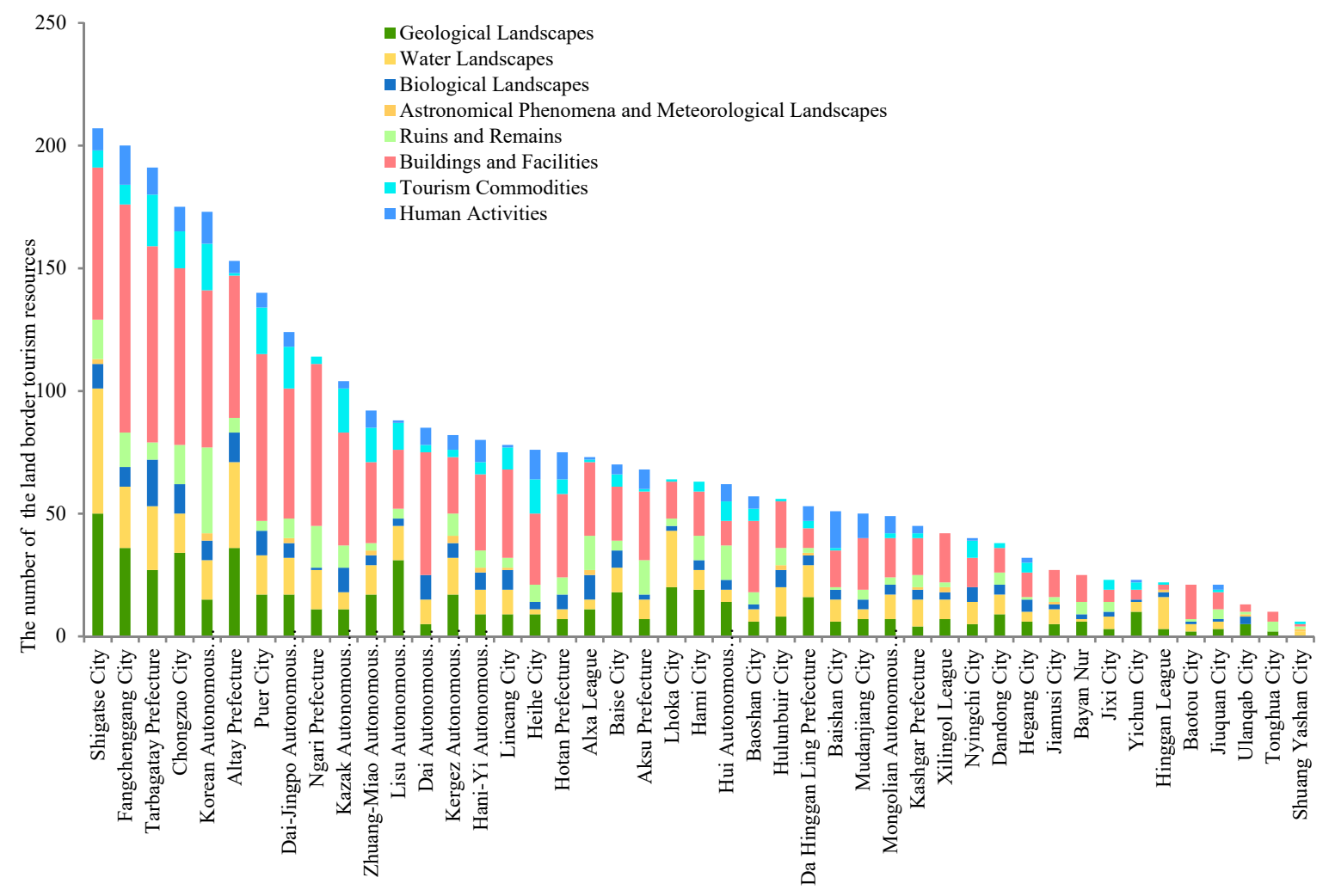

Figure 3. The numbers and types of land border tourism resources at the prefectural scale.

The global Moran's I of land border tourism resources, geological landscapes, water landscapes, biological landscapes, and buildings and facilities were all positively significant at the 0.01 level (Table 3). The global Moran's I of tourism commodities and human activities were both positively significant at the 0.05 level. This means that the spatial agglomeration phenomena of the land tourism resources and the six types of tourism resources are positively clustered at the prefectural scale. In contrast, the global Moran's I of astronomical phenomena and meteorological landscapes and ruins and remains were not significant, which means their distribution is more likely to be random. Thus, the local spatial association analysis was only applied to the total land border tourism resources, geological landscapes, water landscapes, biological landscapes, buildings and facilities, tourism commodities, and human activities (Figure 4).

For the total land border tourism resources, a cluster of prefectural units with more tourism resources and neighboring prefectural units with more tourism resources is apparent in the southwest of China. Shigatse city in Tibet and Chongzuo city and Fangchenggang city in Guangxi even showed a significant cluster effect at the 0.01 level. In contrast, clusters of prefectural units with few tourism resources surrounded by neighbors with few tourism resources are apparent in the northeast of China, including in the prefectural units of Baotou, Ulanqab, Xilingol, and Hinggan in Inner Mongolia and Yichun, Hegang, Jiamusi, Shuangyashan, and Jixi in Heilongjiang. The Korean autonomous prefecture of Yanbian in Jilin was the only significant high-low outlier (Figure 4). 


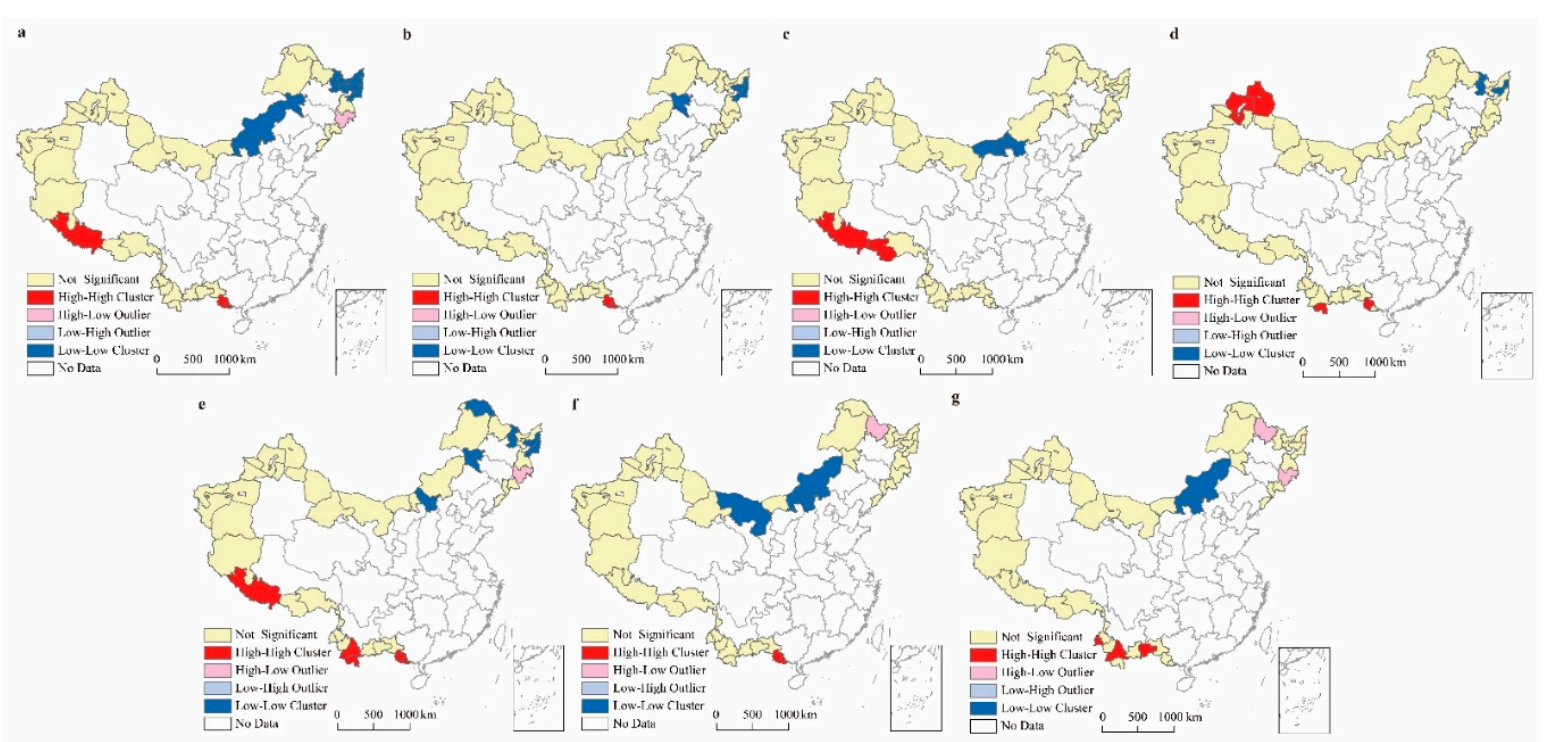

Figure 4. Local indicators of spatial association (LISA) map of land border tourism resources in China at the prefectural scale (a) total land border tourism resources; (b) geological landscapes; (c) water landscapes; (d) biological landscapes; (e) buildings and facilities; (f) tourism commodities; (g) human activities).

\subsection{Spatial Patterns of Land Border Tourism Resources at the County Level}

At the county scale, the largest numbers of land border tourism resources are found in Dongxing, a county-level city in Guangxi (130), followed by Dingri county in Tibet (73) and Fangcheng district in Guangxi (70). The lowest numbers of land border tourism resources are found in the county-level cities Alashankou and Khorgos in Xinjiang, the county-level city Erenhot and Sonid right banner in Inner Mongolia, Jidong county in Heilongjiang and Zhenxing district in Liaoning, all with only five tourism resources. The overall pattern at the county scale showed that more tourism resources are gathered in the southwest of China and fewer tourism resources are in the northeast of China (Figure 5). The spatial variation in land border tourism resources at the county scale showed great differences among different types. The $C V$ of land border tourism resources was $68.72 \%$, and the $C V$ of astronomical phenomena and meteorological landscapes increased dramatically compared with the prefectural scale, reaching $229.06 \%$. The $C V$ of tourism commodities also increased to the second highest at $189.75 \%$. Most types showed greater spatial variation than at prefectural scale, except for water landscapes (Table 3).

The global Moran's I values of the total land border tourism resources, geological landscapes, water landscapes, ruins and remains, buildings and facilities, and human activities were all positively significant at the 0.01 level (Table 3). The global Moran's I of biological landscapes was positively significant at the 0.05 level. This means that the spatial agglomeration phenomena of the land tourism resources and the six types of tourism resources are positively clustered over the border. In contrast, the global Moran's I values of astronomical phenomena and meteorological landscapes and tourism commodities were not significant, which indicates that their distribution is more likely to be random. Thus, the local spatial association analysis was only applied to the total land border tourism resources, geological landscapes, water landscapes, biological landscapes, ruins and remains, buildings and facilities, and human activities (Figure 6).

For the total land border tourism resources, the high-high clusters were significant at the county-scale units of the county-level cities Dongxing and Pingxiang, Jingxi county, Longzhou county, Daxin county, and Fangcheng district in Guangxi; and Funing county and Dai-Lahu-Va autonomous county of Menglian in Yunnan. Twenty-seven county-scale units, located in the north and northeast areas of China, were shown to behave as low-low clusters. The high-low outliers are located in the 
county-scale units of Dingri county in Tibet, and Antu county and the county-level city Hunchun in Jilin. The low-high outliers are located in the county-scale units of Medog in Tibet and Gengma in Yunnan (Figure 6).

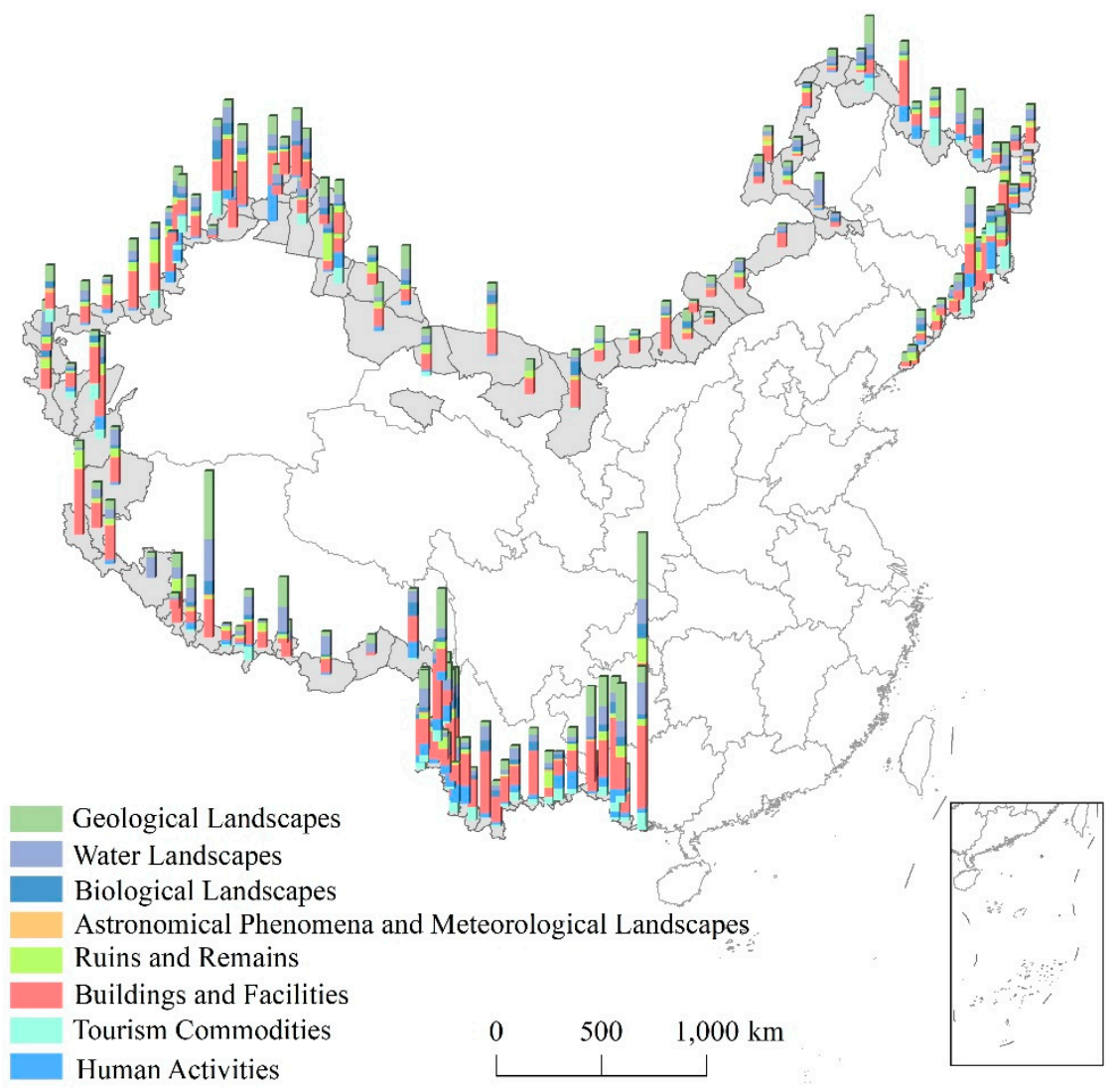

Figure 5. The numbers and types of land border tourism resources at the county scale.

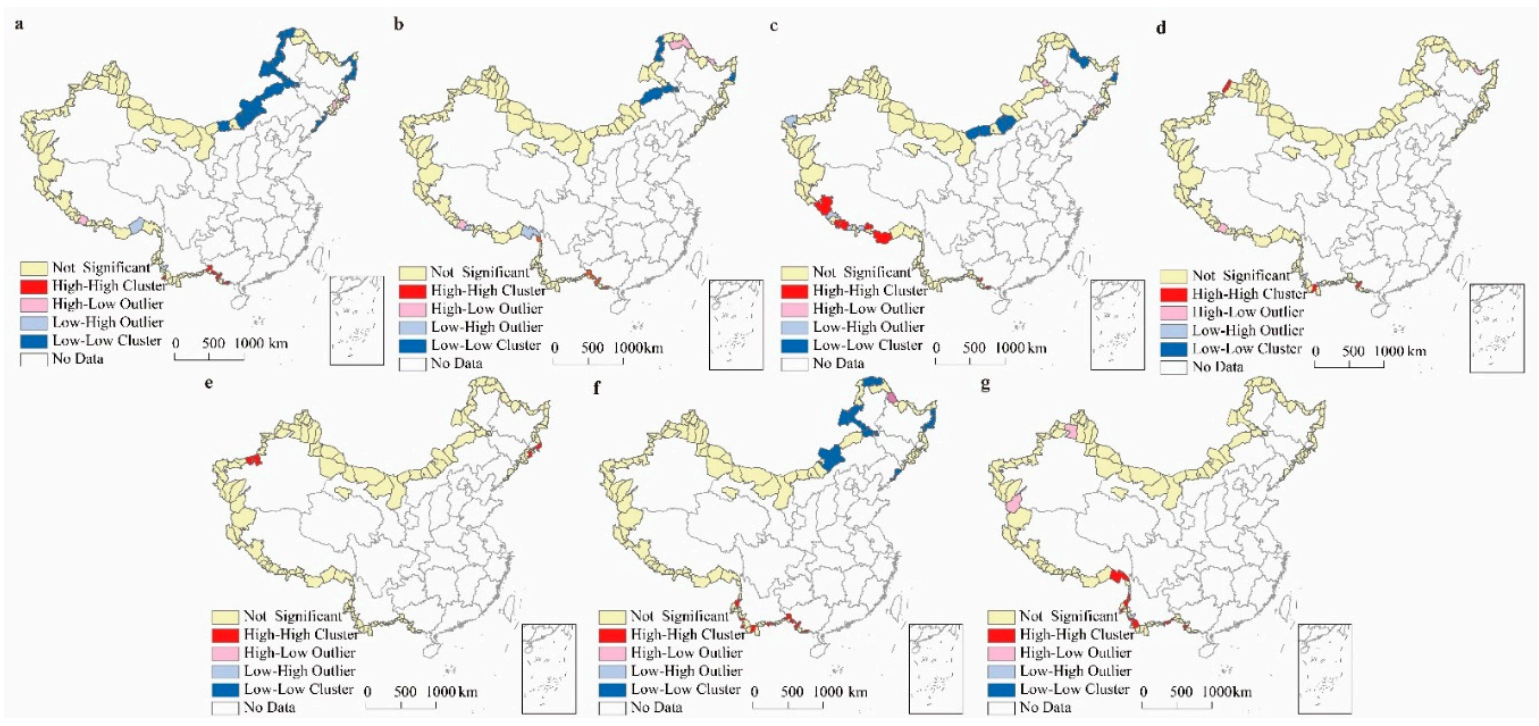

Figure 6. Local indicators of spatial association (LISA) map of land border tourism resources in China at the county scale (a) total land border tourism resources; (b) geological landscapes; (c) water landscapes; (d) biological landscapes; (e) ruins and remains; (f) buildings and facilities; (g) human activities). 


\section{Discussion}

\subsection{Factors Influencing the Spatial Pattern of Land Border Tourism Resources}

Physical factors such as terrain and climate exert significant influences on the distribution of land border tourism resources. As for physical tourism resources, complex terrains and diverse hydrological and meteorological conditions create various landscapes for tourism. In addition, physical factors also have a great impact on the distribution of human tourism resources. The physical factors determine the regional accessibility and communication efficiency with outsiders, resulting in different cultures, building styles, and facilities. The different spatial patterns of border tourism resources in Tibet and Inner Mongolia is a good example. Significant high-high clusters of water landscapes and buildings and facilities are gathered in Tibet, while low-low clusters of water landscapes and buildings and facilities tourism resources are gathered in Inner Mongolia. One reason for the differences might be that the climate in Tibet tends to include more precipitation than that in Inner Mongolia, resulting in the high-high clusters of water landscapes in Tibet. Another reason might be the complex terrain in Tibet, which creates diverse geological landscapes and also contributes to the protection of local traditional culture and folk customs. Therefore, the different spatial patterns of land border tourism resources were probably caused by physical factors, including terrain, climate, and hydrological conditions.

The diversity of regional culture is another factor affecting the spatial pattern of land border tourism resources. Due to their locations and historical factors, the cultures and customs of residents living in the border areas might be similar to those of their neighboring countries, forming unique characteristics compared with other areas in China. For example, the human activities and tourism commodities in the border counties of Inner Mongolia are almost the same as those in Mongolia, and the traditional buildings in the south of Guangxi are similar to those in the north of Vietnam. Thus, for the tourists who want to experience foreign culture but have limited time or money, border tourism would be a nice choice [55]. In addition, if one county has two or three foreign neighbors, its cultural tourism resources will be much more diversified due to the culture interactions. For example, Hunchun, a county level city of Jilin located near Russia and North Korea, has richer tourism commodities than the other land border counties in China. In addition, Mengla county of Yunnan, located next to Laos and Myanmar, has more colorful human activities than its neighboring counties with only one foreign neighbor.

The regional policies are another important influential factor in the development of land border tourism resources. In order to avoid competition with the neighboring counties with high-profile tourism resources, the governments select different types of tourism resources to develop as their first choice [56]. Thus, although the quantity and diversity of tourism resources are similar in some neighboring areas, the spatial patterns of their tourism resources are inconsistent. The high-low and low-high outlies are apparent in most types of land border tourism resources at different scales, which implies different developing policies between the neighboring administrative units. For example, Aihui district, as the county that signed the Treaty of Aigun between the Qing Dynasty and Russia, has many famous historical buildings and facilities. Thus, the government of Aihui district has focused the local tourism on these historical tourism resources. In contrast, Huma county, located near Aihui, choose to develop the geological landscape as a priority, even though it has similar styles of buildings and facilities. Consequently, the composition of land border tourism resources in these two counties is different, and Aihui district has even become a high-low outlier for buildings and facilities.

Another political factor influencing the spatial patterns of land border tourism resources is the cooperation relationships between adjacent cities or counties. There are many huge geographical entities in the border areas covering multiple administrative units in China. However, due to being limited by the administrative divisions, the development of some tourism resources has been independent, even between neighboring counties that belong to the same city. The lack of trans-boundary cooperation could cause environmental degradation on both sides of the border and the unbalanced utilization of trans-boundary resources [57]. For example, the world-famous 
Himalayas mountain ranges are distributed across many counties in Tibet, but the development policies on Himalayas tourism resources in these counties varies a lot. Dingri county in Tibet adopted a positive policy on the development of border tourism, thus the number of tourism resources is much higher in Tibet than in its neighbors with similar physical and human environmental aspects.

Due to the special locations of land border tourism resources, another crucial factor in determining the spatial pattern of land border tourism resources is the political relationships between China and the neighboring countries. Due to the frequent trade with the neighboring countries, the border cities or counties with border ports are always regional hot spots of tourism. For example, Youyi Guan is a famous historical frontier pass in Guangxi and was an important land port between China and Vietnam from West Han Dynasty (206 BC-9 AD). In recent years, due to the stable, good relationship between China and Vietnam, more than 100,000 tourists have visited this historical military construction every year. In 2010, Youyi Guan was even granted an AAAA scenic area status, which is the second highest rank awarded by the China National Tourism Administration. In contrast, communication is limited between the two countries on the controversial border, resulting in the negative development of tourism resources. Near the controversial border between China and India, Medog and Kamba county in Tibet have only nine land border tourism resources.

Last but not least, the public facilities of land border areas influence the tourism development significantly. The regional transportation and accommodation facilities are the basic and supportive factors for tourism development. With better public facilities, the border tourism resources can attract more visitors and greater income. For example, Hunchun city saw an increase of total investment in fixed assets at an annual rate of $8.8 \%$ from 2012-2016, and the construction of its highways, railways, airline, and tourist reception facilities improved significantly. In 2016, the city attracted 2.5 million tourists from home and abroad and gained a 2.8-billion-yuan total tourism revenue, which is 2.7 times and 2.4 times more than in 2012, respectively.

\subsection{Implication for the Development of Land Border Tourism Resources}

Recently, along with the programs "Prospering Frontier Action and Enriching People" and "One Belt One Road Initiative", the Chinese government has paid more and more attention to the development of land border areas. Due to geographical, historical, and political factors, the economy of the border areas is inferior to that of the inland and coastal areas of China. According to the statistics, there are 53 state poverty counties confirmed by the State Council as being located on the land border, accounting for $38.41 \%$ of all land border counties of China. Fortunately, the tourism resources in these poverty counties are relatively abundant (Figure 7). Some poverty county scale units even show high-high clusters, such as Jingxi county, Longzhou county, Daxin county in Guangxi, Funing county, and Dai-Lahu-Va autonomous county of Menglian in Yunnan (Figure 6). Therefore, border tourism is an important way to boost the development of the land border areas of China. In addition, border tourism could improve the mutual understanding between China and its neighbors, which is important for national cooperation and regional stability. Based on the analysis above, the quantity and the diversity of land border tourism resources in China vary significantly, indicating unbalanced tourism development and the potential for better exploitation. Here, we propose five suggestions for the development and management of land border tourism resources in China. 


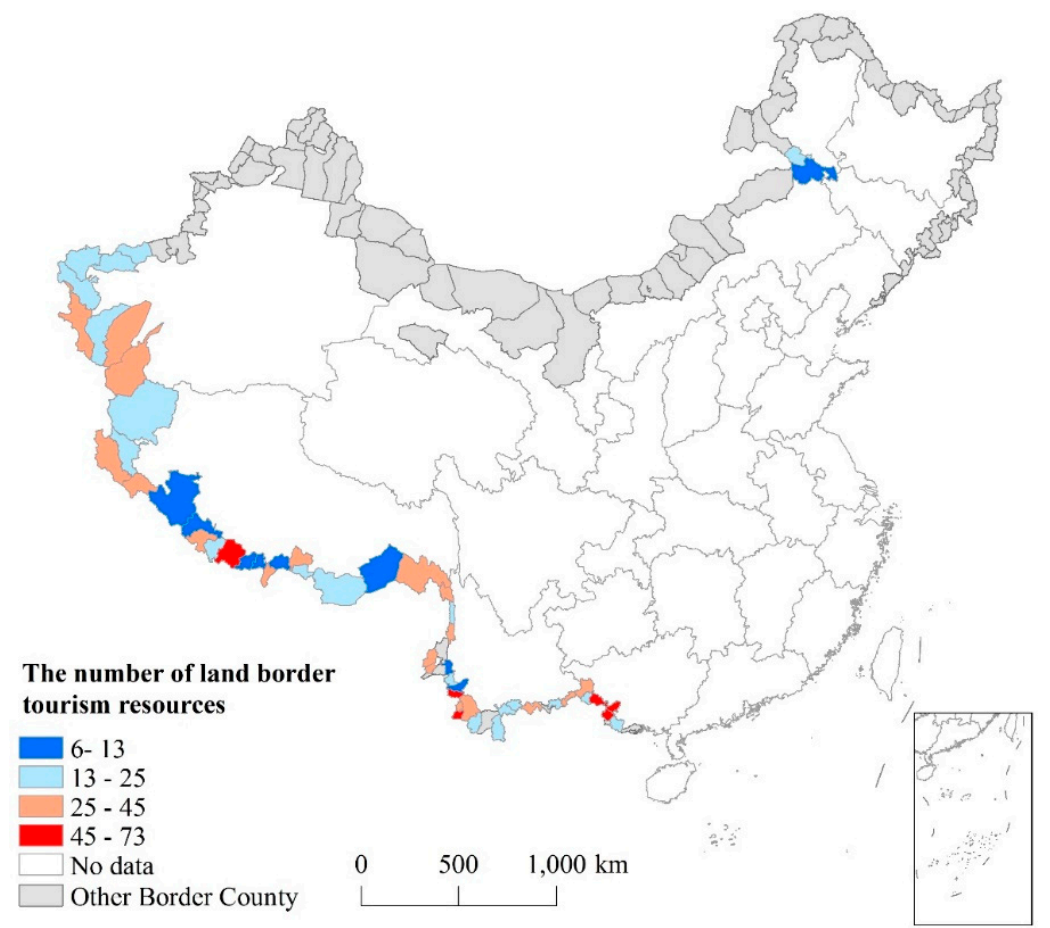

Figure 7. The number of land border tourism resources in the state poverty counties of China.

Firstly, governments should adjust their management policies and develop strategies based on the characteristics of local tourism resources. Different physical environments and social customs cause differences in the quantity, diversity, and quality of land border tourism resources. The government should thoroughly realize the advantages and disadvantages of the tourism resources compared with other areas to facilitate choosing a suitable model for the achievement of sustainable development. For example, the ecological environment in the western land border areas is generally fragile. It is important for the government to measure the impacts of tourism development on the environment, and ecotourism might be a nice choice for the western land border areas. In contrast, the southwest land border areas are rich in various minority ethnic groups with a diverse range of cultures and customs, thus culture tourism could be popular in these areas. The governments could encourage the development of theme hotels and restaurants with local characteristics and establish tourism towns with rich ethnic customs. It is essential to discover the characteristics of land border tourism resources and analyze the factors influencing tourism development to make a scientific development plan for tourism resources.

Secondly, the government should combine different types of land border tourism resources to increase the diversity of local tourism development. The unbalanced development of different types of tourism resources is apparent in the land border areas. In some areas, the development of tourism is over-dependent on the well-known tourism resources but neglects the other types, resulting in a single tourism structure. For example, the prefectural cities of Chongzuo and Fangchenggang in Guangxi are high-high clusters of geological landscapes, ruins and remains, and buildings and facilities. The similar structures of tourism resources have resulted in serious tourism competition between the two cities. In order to avoid regional competition, the governments should adjust their focus to the combinatorial development of various types of tourism resources. The various types of tourism resources would further diversify tourism activities such as ecotourism, adventure tourism, cultural tourism, medical tourism, and rural tourism.

Thirdly, coordination within the different levels of government in China and cross-border cooperation between both domestic and international adjacent administrative units are essential in order to develop effective tourism strategies and avoid duplication of resources. In China, local 
policies usually require approval and financial support from the higher-level government, and the successful implementation of national level initiatives requires the involvement of the lower-level government, which is familiar with the regional culture and local conditions. Thus, the coordination between the higher-level government and local governments should be encouraged when making relative tourism development decisions [12]. In addition, the trans-boundary cooperation within the administrative units of China, and between China and its neighboring countries should be strengthened. The agglomeration phenomenon of land border tourism resources was apparent in some areas with large-scale geographical entities, which indicates that the local governments could investigate the tourism resources together and make integrative development plans. For international cooperation, the neighboring countries could try to establish a tourism collaboration zone, simplify the procedure of entering the counties or cities for the tourists, and hold some festival activities together. It would be wise to establish a tourism cooperation zone to protect shared resources and promote mutual communication along the border areas, such as the Lancang-Mekong river bordering Myanmar, Laos and Vietnam, the Amur-Heilong river bordering Russia, and the Altay Mountains bordering Mongolia and Russia.

Fourthly, the government should give more financial support to the development of tourism infrastructure and services. Due to the complex terrains and relatively backward economies, the transportation and facilities services of the land border areas are far inferior to those of the inland and coastal areas, which influences the tourists' satisfaction and limits land border tourism development. The governments should take some positive measures to finance the construction of tourist facilities, including transportation construction, accommodation, tourism signage, and emergency rescue facilities.

Fifthly, due to the vulnerability of the environment and the sensitivity of the local culture [12], the government should pay more attention to the protection of the authenticity of cultural resources and the integrity of natural resources during exploitation. Many minority groups are gathered in the border areas, and their religions and customs are very different from the developed areas of China. The development of tourism is certain to cause some changes in their social structures and traditional cultures. The cultivation of local cultural confidence and promotion of local ethic culture are necessary for sustainable tourism development.

In summary, it is impossible to propose a policy fit for all land border tourism resources considering the different natures and quantities of the resources available along the entire land border in China. In addition, the economical, administrative, and political-institutional constraints faced by each territory vary significantly. It would be wise to drive the tourism development strategy based on the characteristics of each resource.

\section{Conclusions}

Based on data from 3341 land border tourism resources collected from various sources, this study analyzed the spatial pattern of land border tourism resources in China. New knowledge was acquired regarding the numerical features, spatial variation, and spatial associations of land border tourism resources at different scales in China using GIS and spatial statistic technology. The effects of the physical environment, cultural diversity, local policies, relationships between neighboring countries, and public facilities on forming the pattern were further discussed. Based on these analyses, five suggestions were offered for the regional development of land border tourism in China.

The results showed that the buildings and facilities are the largest first-level type and the comprehensive cultural tourism destination is the largest subtype of land border tourism resources. At different scales, the border between China and Vietnam has the largest number of land border tourism resources, while the border between China and Tajikistan has the smallest number of resources. Shigatse city in Tibet has the largest number of land border tourism resources, while Shuangyashan city in Heilongjiang has the smallest number among all prefectural units. Significant spatial associations were found for the total land border tourism resources, geological landscapes, water landscapes, 
biological landscapes, buildings and facilities, and human activities at both the prefectural scale and the county scale. Overall, the significant high-high clusters and low-low clusters are gathered in the southwest and north of China, respectively. The physical factors, cultural diversity, the regional policies, relationships with neighboring countries, and tourism services are all important factors that influence the distribution and development of land border tourism resources. In order to achieve sustainable utilization of land border tourism resources, it is suggested that the government should adjust their management policies based on the local situations of the tourism resources, carry out combinatorial development of different types of resources, strengthen domestic and international cooperation, improve public facilities, and protect the local environment and ethnic culture.

Our findings contribute to the understanding of land border tourism development in China. The GIS technology and spatial statistic methods used in this paper can be used for other types of tourism resources as well. However, due to the difficulties in data acquisition, the statistics of land border tourism resources in some counties are not complete. In addition, this study only analyzed the factors influencing the spatial pattern of land border tourism resources qualitatively. It would be beneficial to further analyze the factors with quantitative methods. Future studies should evaluate the quality and competitiveness of land border tourism resources in China to drive more practical management policies for border tourism development.

Supplementary Materials: The following are available online at http://www.mdpi.com/2071-1050/11/1/236/s1.

Author Contributions: S.Z. and Y.W. conceived and designed the paper and experiments; S.Z. and L.Z. performed the investigation and data curation; S.Z. and H.J. analyzed the data; S.Z. wrote the paper.

Funding: This research was funded by Ministry of Science and Technology of the People's Republic of China, grant number 2013FY112800.

Conflicts of Interest: The authors declare no conflict of interest.

\section{References}

1. Sofield, T.H.B. Border tourism and border communities: An overview. Tour. Geogr. 2006, 8, 102-121. [CrossRef]

2. Timothy, D.J. Political boundaries and tourism: Borders as tourist attractions. Tour. Manag. 1995, 16, 525-532. [CrossRef]

3. Lim, C. Review of international tourism demand models. Ann. Tour. Res. 1997, 24, 835-849. [CrossRef]

4. Hampton, M.P. Enclaves and ethnicties: The local impacts of Singaporean cross-border tourism in Malaysia and Indonesia. Singap. J. Trop. Geogr. 2010, 31, 239-253. [CrossRef]

5. Anaman, K.A.; Ismail, R.A. Cross-border tourism from Brunei Darussalam to Eastern Malaysia: An empirical analysis. Singap. Econ. Rev. 2002, 47, 65-87. [CrossRef]

6. Prescott, J.R.V. Border landscape. In Political Frontiers and Boundaries (Routledge Library Editions: Political Geography); Routledge: London, UK, 2014; pp. 159-173.

7. Timothy, D.J. Tourism and international borders: Themes and issues. Vis. Leis. Bus. 1998, 17, 3-7.

8. Lord, K.R.; Putrevu, S.; Shi, Y.Z. Cultural influences on cross-border vacationing. J. Bus. Res. 2008, 61, 183-190. [CrossRef]

9. Bradbury, S.L. The impact of security on travelers across the Canada-US border. J. Transp. Geogr. 2013, 26, 139-146. [CrossRef]

10. Martin, E.; Vigne, L. Successful rhino conservation continues in West Bengal, India. Pachyderm 2012, 51, 27-37.

11. Hall, C.M. Biosecurity and wine tourism. Tour. Manag. 2005, 26, 931-938. [CrossRef]

12. Timothy, D.J. Cross-border partnership in tourism resource management: International parks along the US-Canada border. J. Sustain. Tour. 1999, 7, 182-205. [CrossRef]

13. Greer, J. Developing trans-jurisdictional tourism partnerships-Insights from the Island of Ireland. Tour. Manag. 2002, 23, 355-366. [CrossRef]

14. Arrington, A.L. Competing for tourists at Victoria Falls: A historical consideration of the effects of government involvement. Dev. South. Afr. 2010, 27, 773-787. [CrossRef] 
15. Prokkola, E.K. Borders in tourism: The transformation of the Swedish-Finnish border landscape. Curr. Issues Tour. 2010, 13, 223-238. [CrossRef]

16. del Río, J.A.J.; Agüera, F.O.; Cuadra, S.M.; Morales, P.C. Satisfaction in border tourism: An analysis with structural equations. Eur. Res. Manag. Bus. Econ. 2017, 23, 103-112. [CrossRef]

17. Bringas, N. Border Tourism: Characterization and Development Possibilities; COLEF-CESTUR: Tijuana, Mexico, 2004.

18. Gelbman, A.; Timothy, D.J. Border complexity, tourism and international exclaves: A case study. Ann. Tour. Res. 2011, 38, 110-131. [CrossRef]

19. Gelbman, A. Border tourism in Israel: Conflict, peace, fear and hope. Tour. Geogr. 2008, 10, $193-213$. [CrossRef]

20. Timothy, D.J. Borderlands Tourism. Tourism and Political Boundaries; Routledge: London, UK, 2002; pp. 36-81.

21. Wang, D. Hong Kongers' cross-border consumption and shopping in Shenzhen: Patterns and motivations. J. Retail. Consum. Serv. 2004, 11, 149-159. [CrossRef]

22. Shin, Y.S. Tourists' perceptions and attitudes towards political boundaries and tourism. Int. J. Tour. Sci. 2004, 4, 17-37. [CrossRef]

23. Shin, Y.S. Perception differences between domestic and international visitors in the tourist destination: The case of the Borderline, the DMZ area. J. Travel Tour. Mark. 2007, 21, 77-88. [CrossRef]

24. Timothy, D.J.; Tosun, C. Tourists' perceptions of the Canada-USA border as a barrier to tourism at the International Peace Garden. Tour. Manag. 2003, 24, 411-421. [CrossRef]

25. Hale, G. Politics, people and passports: Contesting security, travel and trade on the US-Canadian Border. Geopolitics 2011, 16, 27-69. [CrossRef]

26. Berdell, J.; Ghoshal, A. US-Mexico border tourism and day trips: An aberration in globalization? Latin Am. Econ. Rev. 2015, 24, 15. [CrossRef]

27. Vodeb, K. Cross-border regions as potential tourist destinations along the Slovene-Croatian frontier. Tour. Hosp. Manag. 2010, 16, 219-228.

28. Prokkola, E.K. Resources and barriers in tourism development: Cross-border cooperation, regionalization and destination building at the Finnish-Swedish border. Fennia-Int. J. Geogr. 2008, 186, 31-46.

29. Felsenstein, D.; Freeman, D. Estimating the impacts of crossborder competition: The case of gambling in Israel and Egypt. Tour. Manag. 2001, 22, 511-521. [CrossRef]

30. Chirozva, C. Community agency and entrepreneurship in ecotourism planning and development in the Great Limpopo Transfrontier Conservation Area. J. Ecotour. 2015, 14, 185-203. [CrossRef]

31. Spenceley, A. Tourism in the Great Limpopo Transfrontier Park. Dev. South. Afr. 2006, 23, 649-667. [CrossRef]

32. Spenceley, A. Requirements for sustainable nature-based tourism in transfrontier conservation areas: A southern African Delphi consultation. Tour. Geogr. 2008, 10, 285-311. [CrossRef]

33. Ioannides, D.; Nielsen, P.Å.; Billing, P. Transboundary collaboration in tourism: The case of the Bothnian Arc. Tour. Geogr. 2006, 8, 122-142. [CrossRef]

34. Prokkola, E.K. Cross-border regionalization and tourism development at the Swedish-Finnish Border: “Destination Arctic Circle". Scand. J. Hosp. Tour. 2007, 7, 120-138. [CrossRef]

35. Blasco, D.; Guia, J.; Prats, L. Emergence of governance in cross-border destinations. Ann. Tour. Res. 2014, 49, 159-173. [CrossRef]

36. Scott, D.; McBoyle, G.; Schwartzentruber, M. Climate change and the distribution of climatic resources for tourism in North America. Clim. Res. 2004, 27, 105-117. [CrossRef]

37. Saxena, G.; Ilbery, B. Integrated rural tourism a border case study. Ann. Tour. Res. 2008, 35, $233-254$. [CrossRef]

38. Laing, J.H.; Crouch, G.I. Frontier tourism: Retracing mythic journeys. Ann. Tour. Res. 2011, 38, $1516-1534$. [CrossRef]

39. Weidenfeld, A. Tourism and cross border regional innovation systems. Ann. Tour. Res. 2013, 42, $191-213$. [CrossRef]

40. Nepal, S. Tourism and remote mountain settlements: Spatial and temporal development of tourist infrastructure in the Mt Everest region, Nepal. Tour. Geogr. 2005, 7, 205-227. [CrossRef]

41. Mckercher, B.; Lau, G. Movement patterns of tourists within a destination. Tour. Geogr. 2008, 10, 355-374. [CrossRef] 
42. Connell, J.; Page, S.J. Exploring the spatial patterns of car-based tourist travel in Loch Lomond and Trossachs National Park, Scotland. Tour. Manag. 2008, 29, 561-580. [CrossRef]

43. Xia, J.; Zeephongsekul, P.; Packer, D. Spatial and temporal modelling of tourist movements using Semi-Markov processes. Tour. Manag. 2011, 32, 844-851. [CrossRef]

44. Zhong, L.; Zhang, S.; Shi, Y.; Zhang, A. Evaluation and Utilization Strategies of Land Border Tourism Resources in China. Resour. Sci. 2014, 36, 1117-1124. (In Chinese)

45. Gan, J. The Border Tourism Development in Northeast China; Research on the Border Tourism Regional System in the Northeast China; Northeast Normal University: Jilin, China, 2016; pp. 39-47. (In Chinese)

46. Jelinski, D.E.; Wu, J. The modifiable areal unit problem and implications for landscape ecology. Landsc. Ecol. 1996, 11, 129-140. [CrossRef]

47. Lovie, P. Coefficient of variation. Encycl. Stat. Behav. Sci. 2005, 1, 317-318.

48. Moran, P.A. The interpretation of statistical maps. J. R. Stat. Soc. B 1948, 10, 243-251. [CrossRef]

49. Yang, Y.; Wong, K.K. Spatial distribution of tourist flows to China's cities. Tour. Geogr. 2013, 15, 338-363. [CrossRef]

50. Yang, X.-Z.; Wang, Q. Exploratory space-time analysis of inbound tourism flows to China cities. Int. J. Tour. Res. 2014, 16, 303-312.

51. García-Palomares, J.C.; Gutiérrez, J.; Mínguez, C. Identification of tourist hot spots based on social networks: A comparative analysis of European metropolises using photo-sharing services and GIS. Appl. Geogr. 2015, 63, 408-417. [CrossRef]

52. Anselin, L. The Moran Scatterplot as an ESDA Tool to Assess Local Instability in Spatial Association; Regional Research Institute, West Virginia University: Morgantown, WV, USA, 1993; pp. 111-125.

53. Anselin, L. Local indicators of spatial association-LISA. Geogr. Anal. 1995, 27, 93-115. [CrossRef]

54. Levine, N. CrimeStat III: A Spatial Statistics Program for the Analysis of Crime Incident Locations (Version 3.0); Ned Levine \& Associates: Houston, TX, USA; National Institute of Justice: Washington, DC, USA, 2004.

55. Ning, Z.; Yang, L.; Zhong, L. Space-Time Characteristics of the Chinese Land Border Inbound Tourist Market. Resour. Sci. 2014, 36, 1125-1132. (In Chinese)

56. Shi, Y.; Zhong, L.; Chen, T. Evaluation of Border Tourism Competitiveness at the County Level in China. Resour. Sci. 2014, 36, 1133-1141. (In Chinese)

57. Timothy, D.J. Cooperative tourism planning in a developing destination. J. Sustain. Tour. 1998, 6, 52-68. [CrossRef] 